\title{
Improvement of predictive tools for vapor-liquid equilibrium based on group contribution methods applied to lipid technology
}

Damaceno, Daniela S.; Perederic, Olivia A.; Ceriani, Roberta; Kontogeorgis, Georgios M.; Gani, Rafiqul

Published in:

Fluid Phase Equilibria

Link to article, DOI:

10.1016/j.fluid.2017.12.009

Publication date:

2018

Document Version

Peer reviewed version

Link back to DTU Orbit

Citation (APA):

Damaceno, D. S., Perederic, O. A., Ceriani, R., Kontogeorgis, G. M., \& Gani, R. (2018). Improvement of predictive tools for vapor-liquid equilibrium based on group contribution methods applied to lipid technology. Fluid Phase Equilibria, 470, 249-258. https://doi.org/10.1016/j.fluid.2017.12.009

\section{General rights}

Copyright and moral rights for the publications made accessible in the public portal are retained by the authors and/or other copyright owners and it is a condition of accessing publications that users recognise and abide by the legal requirements associated with these rights.

- Users may download and print one copy of any publication from the public portal for the purpose of private study or research.

- You may not further distribute the material or use it for any profit-making activity or commercial gain

- You may freely distribute the URL identifying the publication in the public portal 


\section{Accepted Manuscript}

Improvement of predictive tools for vapor-liquid equilibrium based on group contribution methods applied to lipid technology

Daniela S. Damaceno, Olivia A. Perederic, Roberta Ceriani, Georgios M. Kontogeorgis, Rafiqul Gani

PII:

$$
\text { S0378-3812(17)30485-5 }
$$

DOI:

Reference: FLUID 11682

To appear in: Fluid Phase Equilibria

Received Date: 9 September 2017

Revised Date: 2 December 2017

Accepted Date: 4 December 2017

Please cite this article as: D.S. Damaceno, O.A. Perederic, R. Ceriani, G.M. Kontogeorgis, R. Gani, Improvement of predictive tools for vapor-liquid equilibrium based on group contribution methods applied to lipid technology, Fluid Phase Equilibria (2018), doi: 10.1016/j.fluid.2017.12.009.

This is a PDF file of an unedited manuscript that has been accepted for publication. As a service to our customers we are providing this early version of the manuscript. The manuscript will undergo copyediting, typesetting, and review of the resulting proof before it is published in its final form. Please note that during the production process errors may be discovered which could affect the content, and all legal disclaimers that apply to the journal pertain. 


\section{Improvement of predictive tools for vapor-liquid equilibrium based}

\section{on group contribution methods applied to lipid technology}

Daniela S. Damaceno ${ }^{1,2}$, Olivia A. Perederic ${ }^{2}$, Roberta Ceriani ${ }^{1}$, Georgios M. Kontogeorgis ${ }^{2}$, Rafiqul Gani ${ }^{2}$

${ }^{1}$ Department of Process and Product Design, University of Campinas, SP-13083-852, Campinas, Brazil

${ }^{2}$ Department of Chemical and Biochemical Engineering, Technical University of Denmark, DK2800 Kgs. Lyngby, Denmark

Abstract

Predictive methodologies based on group contribution methods, such as UNIFAC, play a very important role in the design, analysis and optimization of separation processes found in oils, fats and biodiesel industries. However, the UNIFAC model has well-known limitations for complex molecular structures that the first-order functional groups are unable to handle. In the particular case of fatty systems these models are not able to adequately predict the non-ideality in the liquid phase. Consequently, a new set of functional groups is proposed to represent the lipid compounds, requiring thereby, new group interaction parameters. In this work, the performance of several UNIFAC variants, the Original-UNIFAC, the Linear-UNIFAC, Modified-UNIFAC and the Dortmund-UNIFAC is compared. The same set of experimental data and the parameter estimation method developed by Perederic et al. (2017) have been used. The database of measured data comes from a special lipids database developed in-house (SPEED Lipids database 
at KT-consortium, DTU, Denmark). All UNIFAC models using the new lipid-based parameters show, on average, improvements compared to the same models with their published parameters. There are rather small differences between the models and no single model is the best in all cases.

Keywords: Lipids, activity coefficient models, UNIFAC, Original, Linear, Modified, Dortmund

\section{Introduction}

In the recent years, the oil and fat industry has grown significantly, mainly as a result of increased production of biofuels, such as biodiesel. Among the unit operations required for biodiesel/biofuels production, those involving mass transfer, such as distillation and stripping, are among the most important steps in the separation and purification process. In these cases, the vapor-liquid equilibrium (VLE) description of the multicomponent mixture is essential to map the behavior of the different compounds under process conditions. As a consequence, the availability of predictive tools with acceptable accuracy and wide application for engineering design of oil/fat and biodiesel processes is underlined.

Predictive tools based on the group contribution method consider a mixture or any substance as an aggregate of functional groups present in the molecules that constitute it. Therefore, the mixture properties are the result of the sum of contributions of each of these groups, which are predicted through adjustable group interaction parameters. These group interaction-parameters are estimated through regression with carefully selected experimentally measured data. In the case of pure component properties, the contributions of the groups representing the compounds are used to estimate the corresponding property. Like the mixture properties, measured pure 
component property data are used to estimate the group parameters. The advantage of this type of property estimation method is to allow the calculation of thermophysical properties (e.g. boiling points, heat capacity, critical point, densities) of pure compounds or multicomponent mixtures, for example, phase equilibria (activity coefficients of compounds in liquid phase in equilibrium with a vapor phase) of oil and fats. Thus, the use of predictive models based on group contribution methods in design, analysis and optimization of separation processes of oils, fats and biodiesel industries is very important. In particular, those group contribution methods associated with phase equilibrium are among the most important. Group contribution methods for activity coefficients are a valuable tool for process design in the absence of data or when insufficient or inaccurate data are available [1].

Original UNIFAC (UNIQUAC Functional-group Activity Coefficients) [2] and its variants [3-9] has limitations that are intrinsic to their generality, especially the so-called proximity effects. Other methods based on the group contribution approach share this limitation [10]. These proximity effects are particularly important when two or more functional groups are situated at equal or adjacent positions of the carbon atom. Recent works have indicated that these limitations of the UNIFAC method also affect the predictions involving fatty systems. Cunico et al. [11] and Belting et al. [12], evaluating the Original-UNIFAC and UNIFAC-Dortmund, observed that they were not able to adequately predict the non-ideality of the liquid phase of fatty systems, and they proposed changes in the division and/or interaction parameters of the functional groups.

Considering the limitations due to proximity effects and trying to enhance the accuracy of group contribution methods for estimation of activity coefficients related to applications in lipids technology, this work presents a new matrix of Linear-UNIFAC [5], Modified-UNIFAC [3] and 
69

70

71

72

Dortmund-UNIFAC [4] models, especially suited for the estimation of VLE of mixture with lipids compounds, as well as an evaluation of the performance of the published [3-5] and the new lipid-based model-parameters. For purposes of completion purposes, the performance of the Original-UNIFAC model with its published and lipid-based parameters [13] is also included in the study. The same database and parameter estimation method developed [13] are applied to all UNIFAC-based models.

\section{Models Description}

In group contribution methods, the activity coefficient of compound $i$ in liquid solution is calculated from the sum of the entropic contributions, related to the size and shape differences between molecules, and the residual contribution, which accounts for the intermolecular interactions of functional groups of multicomponent mixtures, as represented by Eq. 1 [10].

$$
\ln \gamma_{i}=\ln \gamma_{i}^{C}+\ln \gamma_{i}^{R}
$$

The general form of the combinatorial-term equation applied to all the UNIFAC models studied in this manuscript is described by Eq. 2. Original-UNIFAC and Linear-UNIFAC models have the same form for the combinatorial part. Modified-UNIFAC and Dortmund-UNIFAC models on the other hand have different volume fractions terms within the combinatorial part, as listed in Table 1. The Modified-UNIFAC [3] model uses a modified volume fraction of $r^{2 / 3}$, as suggested by Kikic et al. [14], while the Dortmund-UNIFAC model is based on volume fraction of $r^{3 / 4}$. Both modified volume fractions are of semi-empirical basis and they are shown to work well for mixtures of compounds with very different sizes [4] but they nevertheless fail for polymer solutions. The Modified-UNIFAC model is the only model that does not have the Staverman- 
91 Guggenheim correction term in the combinatorial part [3]. The surface and volume parameters used for the Original-, Linear- and Modified-UNIFAC models are determined through Bondi's method [15], while for the Dortmund-UNIFAC model they are fitted from experimental data together with group interaction-parameters [4]. This poses a problem for extension of the Dortmund-UNIFAC model for the lipid-compounds and regression of the group-interaction parameters.

The residual term of Eq. 1 has the same expression for all models (Eq. 3). The difference between the models is represented by the group-group interaction parameter expression $\left(a_{m n}\right)$, as represented by Eq.6 and given in Table 2. For Original-UNIFAC model the binary group-

100 interaction parameters are temperature independent. In Linear- and Modified-UNIFAC models

101 the group-interaction parameters are temperature dependent. In Dortmund-UNIFAC model the

102 group-interaction parameters are temperature dependent but a different function is employed.

$104 \ln \gamma_{i}^{C}=\ln \frac{r_{i}^{C_{0}}}{\sum_{j} x_{j} r_{j}^{C_{0}}}+1-\frac{r_{i}^{C_{0}}}{\sum_{j} x_{j} r_{j}^{C_{0}}}-C_{1}\left(\ln \left(\frac{\Phi_{i}}{\theta_{i}}\right)+1-\frac{\Phi_{i}}{\theta_{i}}\right)$

$105 \Phi_{i}=\frac{r_{i}}{\sum_{j} x_{j} r_{j}}$

$106 \quad \theta_{i}=\frac{q_{i}}{\sum_{j} x_{j} q_{j}}$

107 Table 1. $C_{0}$ and $C_{l}$ of Eq. 2

\begin{tabular}{lcc}
\hline Model & $C_{0}$ & $C_{l}$ \\
\hline Original-UNIFAC & 1 & $5 q_{i}$ \\
Linear-UNIFAC & 1 & $5 q_{i}$ \\
Modified-UNIFAC & $2 / 3$ & 0 \\
Dortmund-UNIFAC & $3 / 4$ & $5 q_{i}$ \\
\hline
\end{tabular}


$\ln \gamma_{i}^{R}=\sum_{K}^{\text {groups }} v_{k}^{(i)}\left[\ln \Gamma_{k}-\ln \Gamma_{k}^{(i)}\right]$

$110 \quad \ln \Gamma_{k}=Q_{k} \cdot\left[1-\ln \left(\sum_{m} \Theta_{m} \Psi_{m k}\right)-\sum_{m}\left(\theta_{m} \Psi_{m k} / \sum_{n} \Theta_{n} \Psi_{n m}\right)\right]$

$111 \Theta_{m}=\frac{Q_{m} X_{m}}{\sum_{n} Q_{n} X_{n}}$

$$
X_{m}=\frac{\sum_{i}^{M} v_{m}^{(i)} x_{i}}{\sum_{i}^{M} \sum_{j}^{N} v_{j}^{(i)} x_{i}}
$$

$113 \Psi_{m n}=\exp \left(\frac{-a_{m, n}}{T}\right)$

$114 a_{m, n}=A_{0} a_{m n, 0}+A_{1} a_{m n, 1}+A_{2} a_{m n, 2}$

115

Table 2. $A_{0}, A_{1}$ and $A_{2}$ of Eq. 6

\begin{tabular}{lccc}
\hline Model & $A_{0}$ & $A_{1}$ & $A_{2}$ \\
\hline Original-UNIFAC & 1 & 0 & 0 \\
Linear-UNIFAC & 1 & $T-T_{0}$ & 0 \\
Modified-UNIFAC & 1 & $T-T_{0}$ & $T \ln \left(T_{0} / T\right)+T-T_{0}$ \\
Dortmund-UNIFAC & 1 & $T$ & $T^{2}$ \\
\hline
\end{tabular}

$T_{0}$ is reference temperature $\left(T_{0}=298.15 \mathrm{~K}\right)$

\section{Parameter Estimation Method}

120 The estimation of a new set of group-interaction parameters for Linear-UNIFAC, Modified-

121 UNIFAC and Dortmund-UNIFAC models dedicated to systems with lipid compounds was

122 performed using the systematic parameter estimation method of Perederic et al. [13] and

123 employing an in-house database, SPEED Lipids Database, also used by Perederic et al. [13]. The

124 method is divided into three hierarchical parts: a) data collection and analysis; b) data 
organization and selection; and finally c) parameter estimation according to an estimation order and validation. All parts are hereafter briefly described.

\subsection{Data Collection and Analysis}

Considering the SPEED Lipids Database [13] is already available, according to the employed method [13], the next step is to analyze the collected experimental data. Thus, pure compound data availability (e.g.: vapor pressure) and transcript errors (outlier points) are checked. Also, thermodynamic consistency tests [16] are applied to all collected data sets. The TDE (ThermoData Engine) software from NIST is used to calculate the quality factor $\left(Q_{V L E}\right)$ for all binary systems. Note that the same data and analysis are also used by Perederic et al. [13].

\subsection{Data Organization and Selection}

The first step of the data organization and selection is the compound group definition and assignment. In this step the main groups and subgroups of the mixtures are defined and identified (see Table 3). The main groups and subgroups of the UNIFAC models are listed and assigned to represent the compounds found in the VLE datasets, in this case the SPEED Lipids database. The group selection was based on the Original-UNIFAC model division/assignment [13]. All the compounds found in this database are represented by the selected model groups and subgroups. Also, the two new functional groups proposed by Perederic et al [13] to better describe systems containing glycerol $[13,17-18]$ and acylglycerols $[13,17]$, are used in this work, which are GLY and $\mathrm{OH}_{\text {acyl }}$ groups. In this work, all UNIFAC models have the same groups division, however, the subgroups of Dortmund-UNIFAC has an exception [6], as this UNIFAC-based model has two $\mathrm{OH}$ subgroups divisions for $R_{k}$ and $Q_{k}$ parameters (see Table 3), the $\mathrm{OH}$ primary $\left(\mathrm{OH}_{\mathrm{p}}\right)$ and 
148 secondary $\left(\mathrm{OH}_{\mathrm{s}}\right)$. It is important to underline that, the same $\mathrm{OH}_{\mathrm{p}}$ and $\mathrm{OH}_{\mathrm{s}}$ division was applied to

149 the $\mathrm{OH}_{\text {acyl }}$ group for Dortmund-UNIFAC (see Table 3). For this case, the monoacylglycerols,

150 which have two $\mathrm{OH}_{\text {acyl }}$ groups, where described with one $\mathrm{OH}_{\text {acyl,p }}$ and one $\mathrm{OH}_{\text {acyl,s. }}$. For example,

151 the system oleic acid + ethanol is represented by the following main groups: $\mathrm{CH}_{2}, \mathrm{CH}=\mathrm{CH}, \mathrm{OH}$

152 and $\mathrm{COOH}$. In this example, the $\mathrm{OH}$ subgroup is $\mathrm{OH}$ for Linear- and Modified-UNIFACs, and

153 OHp (primary) for Dortmund-UNIFAC. The surface and volume parameters for the functional

154 groups used are given in Table 3.

155

156 Table 3. Area $\left(Q_{k}\right)$ and volume $\left(R_{k}\right)$ parameters for the groups used for the UNIFAC models.

\begin{tabular}{|c|c|c|c|c|c|}
\hline \multirow{2}{*}{ Main Group } & \multirow{2}{*}{ Sub group } & \multicolumn{2}{|c|}{ Original-, Linear- and Modified-UNIFAC [10] } & \multicolumn{2}{|c|}{ Dortmund-UNIFAC [6] } \\
\hline & & $R_{k}$ & $Q_{k}$ & $R_{k}$ & $Q_{k}$ \\
\hline \multirow{3}{*}{$\mathrm{CH}_{2}$} & $\mathrm{CH} 3$ & 0.9011 & 0.8480 & 0.6325 & 1.0608 \\
\hline & $\mathrm{CH} 2$ & 0.6744 & 0.5400 & 0.6325 & 0.7081 \\
\hline & $\mathrm{CH}$ & 0.4469 & 0.2280 & 0.6325 & 0.3554 \\
\hline \multirow[t]{2}{*}{$\mathrm{C}=\mathrm{C}$} & $\mathrm{CH}=\mathrm{CH}$ & 1.1167 & 0.8670 & 1.2832 & 1.2489 \\
\hline & $\mathrm{OH}$ & 1.0000 & 1.2000 & - & - \\
\hline \multirow[t]{2}{*}{$\mathrm{OH}$} & $\mathrm{OHp}^{* \mathrm{a}}$ & - & - & 1.2302 & 0.8927 \\
\hline & $\mathrm{OHs}^{* \mathrm{a}}$ & & - & 1.0630 & 0.8663 \\
\hline \multirow{2}{*}{$\begin{array}{l}\mathrm{CH}_{3} \mathrm{OH} \\
\mathrm{H}_{2} \mathrm{O}\end{array}$} & $\mathrm{CH} 3 \mathrm{OH}$ & 1.4311 & 1.4320 & 0.8585 & 0.9938 \\
\hline & $\mathrm{H} 2 \mathrm{O}$ & 0.9200 & 1.4000 & 1.7334 & 2.4561 \\
\hline \multirow{4}{*}{$\begin{array}{l}\mathrm{CH}_{3} \mathrm{CO} \\
\mathrm{CCOO} \\
\mathrm{COOH}\end{array}$} & $\mathrm{CH} 3 \mathrm{CO}$ & 1.6724 & 1.4480 & 1.7048 & 1.6700 \\
\hline & $\mathrm{CH} 2 \mathrm{COO}$ & 1.6764 & 1.4200 & 1.2700 & 1.4228 \\
\hline & $\mathrm{COOH}$ & 1.3013 & 1.2240 & 0.8000 & 0.9215 \\
\hline & $\mathrm{OH}_{\text {acyl }}$ & 1.0000 & 1.2000 & - & - \\
\hline \multirow[t]{2}{*}{$\mathrm{OH}_{\mathrm{acyl}}{ }^{* \mathrm{~b}}$} & $\mathrm{OH}_{\mathrm{acyl}, \mathrm{p}}{ }^{{ }_{\mathrm{c}}}$ & - & - & 1.2302 & 0.8927 \\
\hline & $\mathrm{OH}_{\mathrm{acyl}, \mathrm{s}}{ }^{* \mathrm{c}}$ & - & - & 1.0630 & 0.8663 \\
\hline \multirow{2}{*}{$\mathrm{GLY}^{* \mathrm{~d}}$} & $\mathrm{GLY}^{* \mathrm{e}}$ & 4.7957 & 4.9080 & - & - \\
\hline & $\mathrm{GLY}^{* \mathrm{f}}$ & - & - & 5.4209 & 4.4233 \\
\hline
\end{tabular}

$157{ }^{*}$ OHp and OHs subgroups are used only for Dortmund UNIFAC

$158{ }^{* b}$ OHacyl describes mono- and diacylglycerols molecules and uses same R and Q as OH group

$159{ }^{* c}$ For Dortmund UNIFAC monoacylglycerols are described with one $\mathrm{OH}_{\text {acyl,p }}$ and one $\mathrm{OH}_{\text {acyl,s }}$, while diacyglycerols

160 are described with one $\mathrm{OH}_{\mathrm{acyl}, \mathrm{p}}$

$161{ }^{*}$ GLY represents the glycerol molecule. R and Q parameters are calculated from contribution of constitutive groups 
${ }^{*}$ For all UNIFAC models except Dortmund GLY is considered as $2 \mathrm{CH}_{2}, 1 \mathrm{CH}, 3 \mathrm{OH}$

163

${ }^{* \mathrm{f}}$ For Dortmund UNIFAC GLY is considered as $2 \mathrm{CH}_{2}, 1 \mathrm{CH}, 2 \mathrm{OHp}, 1 \mathrm{OHs}$

164

165 The second step of the data organization and selection is data category assignment and quality

166 sorting. The data organization algorithm of Perederic et al. [13] is used to assign the data in

167 different category-groups according to binary-interaction provided. A category-group contains

168 VLE data sets that involve the same binary group interaction parameters. The Algorithm A

169 provides the following notation for the category-groups: X.M.N, where: $\mathrm{X}$ is the number of

170 group-interaction parameters involved within a category-group, $\mathrm{M}$ is the number of binary pairs

171 that need to be estimated, and $\mathrm{N}$ is the type of involved pairs of the mixture (the user can select

172 the order of parameter estimation and this will not affect the final result). Examples are presented

173 in Table 4. The Algorithm A and more details of the method are presented by Perederic et al.

174 [13].

175

176 Table 4. Data organization through Algorithm A

\begin{tabular}{|c|c|c|c|c|c|}
\hline $\begin{array}{c}\text { Binary } \\
\text { systems }\end{array}$ & $\begin{array}{l}\text { Interaction } \\
\text { pars }\end{array}$ & $\mathrm{X}$ & M & $\mathrm{N}$ & $\begin{array}{l}\text { Category } \\
\text {-groups: } \\
\text { X.M.N }\end{array}$ \\
\hline $\begin{array}{l}\text { octanoic } \\
\text { acid }+ \\
\text { hexanoic } \\
\text { acid }\end{array}$ & $\mathrm{CH}_{2}-\mathrm{COOH}$ & $\begin{array}{l}\mathrm{X}=1 \text {, one pair } \\
\text { of interaction } \\
\text { parameter }\end{array}$ & $\begin{array}{l}\mathrm{M}=1 \text {, one pair of } \\
\text { interaction parameter } \\
\text { to be estimated }\end{array}$ & $\begin{array}{l}M=1 \text {, the user can select } \\
\text { the order to estimate, this } \\
\text { order will not affect the } \\
\text { next step. }\end{array}$ & 1.1 .1 \\
\hline $\begin{array}{l}\text { ethyl } \\
\text { myristate + } \\
\text { ethyl } \\
\text { palmitate }\end{array}$ & $\mathrm{CH} 2-\mathrm{CCOO}$ & $\begin{array}{l}\mathrm{X}=1 \text {, one pair } \\
\text { of interaction } \\
\text { parameter }\end{array}$ & $\begin{array}{l}\mathrm{M}=1 \text {, one pair of } \\
\text { interaction parameter } \\
\text { to be estimated }\end{array}$ & $\begin{array}{l}M=2, \text { the user can select } \\
\text { the order to estimate, this } \\
\text { order will not affect the } \\
\text { next step. }\end{array}$ & 1.1 .2 \\
\hline $\begin{array}{c}\text { methyl } \\
\text { dodecanoate } \\
+ \text { methanol }\end{array}$ & $\begin{array}{l}\mathrm{CH}_{2}-\mathrm{CCOO} ; \\
\mathrm{CH}_{2^{-}} \\
\mathrm{CH}_{3} \mathrm{OH} ; \\
\mathrm{CCOO}- \\
\mathrm{CH}_{3} \mathrm{OH}\end{array}$ & $\begin{array}{l}\mathrm{X}=3 \text {, three pairs } \\
\text { of interaction } \\
\text { parameters }\end{array}$ & $\begin{array}{l}\mathrm{M}=2 \text {, two pairs of } \\
\text { interaction parameter } \\
\text { to be estimated, } \\
\text { because } \mathrm{CH} 2-\mathrm{CCOO} \\
\text { was estimated in step } \\
1.1 .2\end{array}$ & $\begin{array}{l}M=1 \text {, the user can select } \\
\text { the order to estimate, this } \\
\text { order will not affect the } \\
\text { next step. }\end{array}$ & 3.2 .1 \\
\hline
\end{tabular}




\begin{tabular}{|c|c|c|c|c|c|}
\hline $\begin{array}{c}\text { methyl } \\
\text { dodecanoate } \\
+ \text { ethanol }\end{array}$ & $\begin{array}{l}\mathrm{CH}_{2}-\mathrm{CCOO} ; \\
\mathrm{CH}_{2}-\mathrm{OH} ; \\
\mathrm{CCOO}-\mathrm{OH}\end{array}$ & $\begin{array}{l}X=3 \text {, three pairs } \\
\text { of interaction } \\
\text { parameters }\end{array}$ & $\begin{array}{l}\mathrm{M}=2 \text {, two pairs of } \\
\text { interaction parameter } \\
\text { to be estimated, } \\
\text { because } \mathrm{CH} 2-\mathrm{CCOO} \\
\text { was estimated in step } \\
1.1 .2\end{array}$ & $\begin{array}{l}\mathrm{M}=2 \text {, the user can select } \\
\text { the order to estimate, this } \\
\text { order will not affect the } \\
\text { next step }\end{array}$ & 3.2 .2 \\
\hline
\end{tabular}

177

178

179

180

181

182

183

184

185

186

187

188

189

190

191

192

193

194

195

196

The third step of data organization and selection is the data selection. The best data is chosen by using a selection algorithm, Algorithm B. The foundation of this step is the quality factor and the data availability. Each category-group is independently evaluated with this algorithm. If there are data sets with quality value equal or higher than 0.5 those come first in the evaluation list (descending order). Then, if a binary system has quality factor below 0.5 , the next step is to evaluate if, in this category-groups, there are other systems with quality factor above 0.5 . If there are indeed other systems, the data set is not selected, but if there are no other systems available, the data set is selected. For example: the system octanoic acid + hexanoic acid, from the category-group: 1.1.1, has a quality factor equal to 0.650 , which means, that this system will be used for parameter estimation. Another example, the system methyl dodecanoate + ethanol, from the category-group 3.2.2, has quality factor equal to 0.250 , and the only other available system in this category-group has also quality factor equal to 0.250 . According to the algorithm, both systems will be used for the estimation. The Algorithm B and more details are given in [13].

Table 5 gives the results of organization and selection part of the method. The same datasets are selected/used for parameter estimation as in Perederic et al. [13], ensuring thus a fair comparison between all UNIFAC-based models. Table 5 lists the order in which the data and corresponding groups are to be estimated, the number of available systems and the number of selected systems used for estimation of the interaction parameters in each category-group. 
197 Table 5. Data organization and selection of binary mixtures database used for parameter estimation [13]

\begin{tabular}{|c|c|c|c|c|}
\hline \multirow{2}{*}{$\begin{array}{l}\text { Category } \\
\text {-group }^{\mathrm{a}}\end{array}$} & \multicolumn{2}{|c|}{ Binary system type } & \multirow{2}{*}{$\begin{array}{l}\text { Availabl } \\
\text { e } \\
\text { systems }\end{array}$} & \multirow{2}{*}{$\begin{array}{l}\text { Selecte } \\
\text { d } \\
\text { systems }\end{array}$} \\
\hline & Compound I & Compound II & & \\
\hline 1.1.1. & Saturated Fatty Acids & Saturated Fatty Acids & 23 & 4 \\
\hline 1.1.2. & Saturated Ester & Saturated Ester or Hydrocarbon & 26 & 9 \\
\hline 1.1.3. & Glycerol & Methanol & 20 & 9 \\
\hline 1.1.4. & Glycerol & Water & 44 & 14 \\
\hline 3.1.1. & Saturated Fatty Acids & Saturated Ester & 1 & 1 \\
\hline 3.2.1. & Saturated Ester & Methanol & 5 & 5 \\
\hline 3.2.2. & Saturated. Ester & Ethanol & 2 & 2 \\
\hline 3.2.3. & Saturated Monoacylglycerol & Saturated Ester & 2 & 2 \\
\hline 3.2.4. & Glycerol & Saturated Alcohol & 34 & 11 \\
\hline 3.2.5. & Unsaturated Fatty Acids & $\begin{array}{l}\text { Saturated Fatty Acid or } \\
\text { Hydrocarbon }\end{array}$ & 3 & 1 \\
\hline 3.2.6. & $\begin{array}{l}\text { Unsaturated Ester or } \\
\text { Triacylglycerol }\end{array}$ & Saturated Ester or Hydrocarbon & 3 & 2 \\
\hline 6.1.1. & Saturated Monoacylglycerol & Saturated Fatty Acids & 2 & 2 \\
\hline 6.1.2. & Unsaturated. Ester & Methanol & 2 & 1 \\
\hline 6.1.3. & Unsaturated Ester & Ethanol & 2 & 2 \\
\hline 6.1.4. & Unsaturated Fatty Acids & Methanol & 1 & 1 \\
\hline 6.1.5. & Saturated Fatty Acids & Saturated Alcohol & 2 & 2 \\
\hline 6.3.1. & Unsaturated Triacylglycerol & Acetone & 1 & 1 \\
\hline 6.3.2. & Saturated Fatty Acids & Acetone & 1 & 1 \\
\hline
\end{tabular}

${ }^{\mathrm{a}}$ The category-group is described in Data Organization and Selection section [13]

\subsection{Parameter Estimation and Validation}

201 The parameter estimation task is performed by minimization of the summation of least squares of

202 the pressure, as the objective function (Eq. 9) shows. The optimization problem is solved with

203 the Harwell subroutine VA07AD [19]; in this way, the full set of parameters can be regressed

204 efficiently and quickly [13].

$F_{o b j}=\sum_{i}\left(\frac{P^{\text {experimental }}-P^{\text {calculated }}}{P^{\text {experimental }}}\right)_{i}^{2}+\frac{1}{\beta} \sum_{m} \sum_{n}\left(a_{m n}-a_{m n}^{0}\right)^{2}$

206 where, $F_{o b j}$ is the objective function, $P^{\text {experimental }}$ is the experimental pressure, and $P^{\text {calculated }}$ is the

207 calculated pressure, $a_{m n}$ is the estimated binary interaction parameter, and $a_{m n}^{0}$ is the initial value 
of the binary interaction parameter. The initial values are in this work the Linear- [5], Modified-

[3] and Dortmund- [4] UNIFAC model group-interaction parameter values, or zero for the GLY and $\mathrm{OH}_{\text {acyl }}$ interactions. $\beta$ is an empirical term, that it can range from $10^{3}$ up to $10^{5}$, and in this work was set equal to $10^{5}$ [13], based on trial and error from several regressions, and monitoring the first and second parts of Eq 9 [11,17,20]. So, the first part of Eq. 9 represents the residual pressure, and the second part is the regularization term, which only the most sensitive parameters are allowed to deviate from their nominal values $\left(a_{m n}^{0}\right)$, avoiding unreliable values to the estimated parameters $\left(a_{m n}\right)[11,17,20]$.

216 Finally, to evaluate the performance of the models, all data sets from the SPEED Lipids database 217 are employed to compare them with those predicted with the new parameters and the published 218 parameters. For this purpose, the average relative deviation (ARD, \%), Eq. 10, is used.

$A R D(\%)=1 / N \sum_{i=1}^{N}\left|\frac{P^{\text {exp erimental }}-P^{\text {calculated }}}{P^{\text {exp erimental }}}\right| .100$

221 where, $A R D$ is the average relative deviation in $\%, P^{\text {experimental }}$ is the experimentally measured 222 pressure, and $P^{\text {calculated }}$ is the calculated pressure.

\section{Results and Discussion}

225 New binary interaction parameters for lipids systems were regressed for the Linear-, Modified226 and Dortmund-UNIFAC models. All the new, lipids-based group-interaction parameters are 227 given in Table 6, along with the parameters for Original-UNIFAC model [13]. The temperature ranges for the VLE data for each binary system is also given in Table 6. 
Table 7 lists the ARD (\%) for all VLE binary datasets retrieved from the SPEED lipids database in terms of category-group of the dataset for all the UNIFAC-based models with their published parameters and with the lipids-based group interaction parameters from this work. Furthermore, Table 7 gives the consistency test scores $\left(Q_{V L E}\right)$ for each data-type (category-group) of the mixtures from the database, indicating the quality of the data.

In general, the Linear-UNIFAC model with lipids-based group-interaction parameters show the best performance as it has the lowest overall deviation of about $8.9 \%$. This is about $1 \%$ better than the Dortmund-UNIFAC model, which is the second best model (also with lipids-based group-interaction parameters). The Modified-UNIFAC using lipids-based group interaction parameters show the lowest deviation for the category-group of saturated fatty acid + saturated ester mixtures $(\mathrm{ARD}=1.5 \%)$. Also, lipids-based Dortmund-UNIFAC model gives the best performance for the category-group of saturated ester + saturated ester or hydrocarbon mixtures with $\mathrm{ARD}=4.8 \%$. Still, the general conclusion is that differences between the UNIFAC-based models with the lipids-based group-interaction parameters is rather small as all four models have deviations are around 8-14\%. All four models perform far better than when the published parameters are used where the deviations are about or above $20 \%$.

245 Figure 1 shows the performance of all models (using published and lipids-based group246 interaction parameters) for the system dodecanoic acid + methyl dodecanoate at $0.5 \mathrm{kPa}$ [21]. All 247 models show similar behavior, and better prediction is achieved with the lipids-based group248 interaction parameters (given in Table 6). 


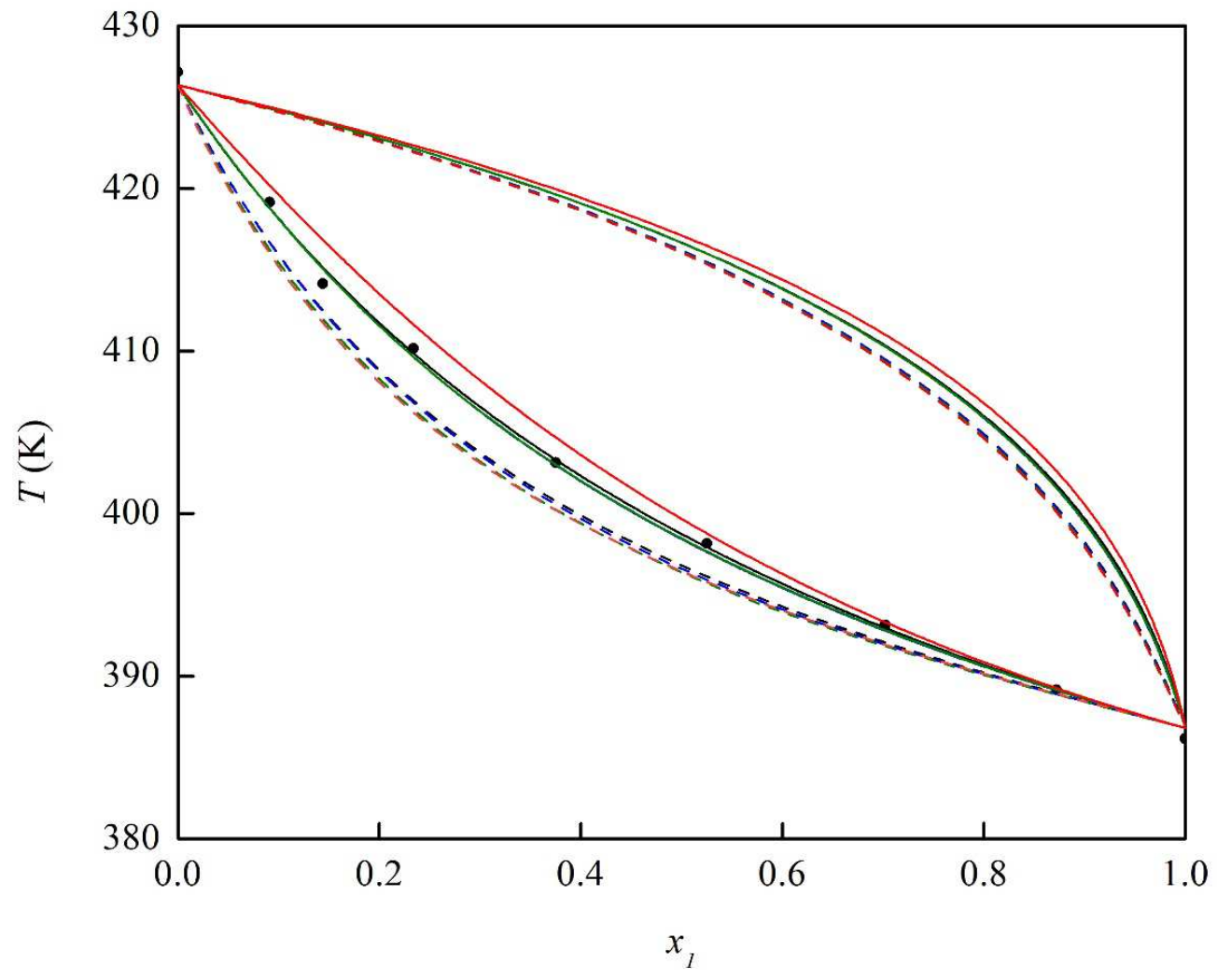

251 Figure 1. Binary system methyl dodecanoate $\left(x_{1}\right)+$ dodecanoic acid $\left(x_{2}\right)$ at $0.5 \mathrm{kPa}$. Experimental data [21] (•). Published parameters models: Original- (--), Linear- (--) Modified- (--) and Dortmund-UNIFAC

(--). Lipids-based group interaction parameters models: Original- (-), Linear- (-), Modified- (一) and Dortmund-UNIFAC (一)

Figure 2 shows the performance of the new group GLY (glycerol group) for the binary system

257 glycerol + water at $14.19 \mathrm{kPa}$ [22]. The Linear- and Modified-UNIFAC models with lipids-based 258 group-interaction parameters have the best predictions for this system, which is the most 259 complex among all systems considered (with deviations around 50\% for the best performing 260 models). The ARD (\%) for the group-categories: glycerol + methanol, glycerol + water and 261 glycerol + alcohols, show that all UNIFAC-based models with lipids-based group-interaction parameters have similar performances, and lower deviations when compared with UNIFAC- 
based models with published parameters (given in Table 7). The Dortmund-UNIFAC model with

264 published parameters give the highest deviation for the group-category glycerol + water, while 265 with the lipids-based group-interaction parameters the same model showed a significant 266 improvement, a reduction from an ARD of $198 \%$ [4] to 56\% (this work). It is important to 267 highlight that for the calculations with the published UNIFAC parameters the glycerol compound 268 is considered as $2 \mathrm{CH}_{2}, 1 \mathrm{CH}$ and $3 \mathrm{OH}$, except for Dortmund-UNIFAC, where glycerol is 269 considered as $2 \mathrm{CH}_{2}, 1 \mathrm{CH}, 2 \mathrm{OH}_{\mathrm{p}}$ and $1 \mathrm{OH}_{\mathrm{s}}$. The deviations for all glycerol-containing 270 mixtures (with water, methanol or other alcohols) are the highest among all systems considered. 271 These are cross-associating systems with very strong hydrogen bonding both self- and cross272 associations. The UNIFAC-models account for such effects only indirectly (interaction 273 parameters and local composition concept) and better performance for such complex mixtures 274 can be obtained with association equations of state like CPA [23] and SAFT [24], as shown in 275 literature by Tsivintzelis et al. [25] 


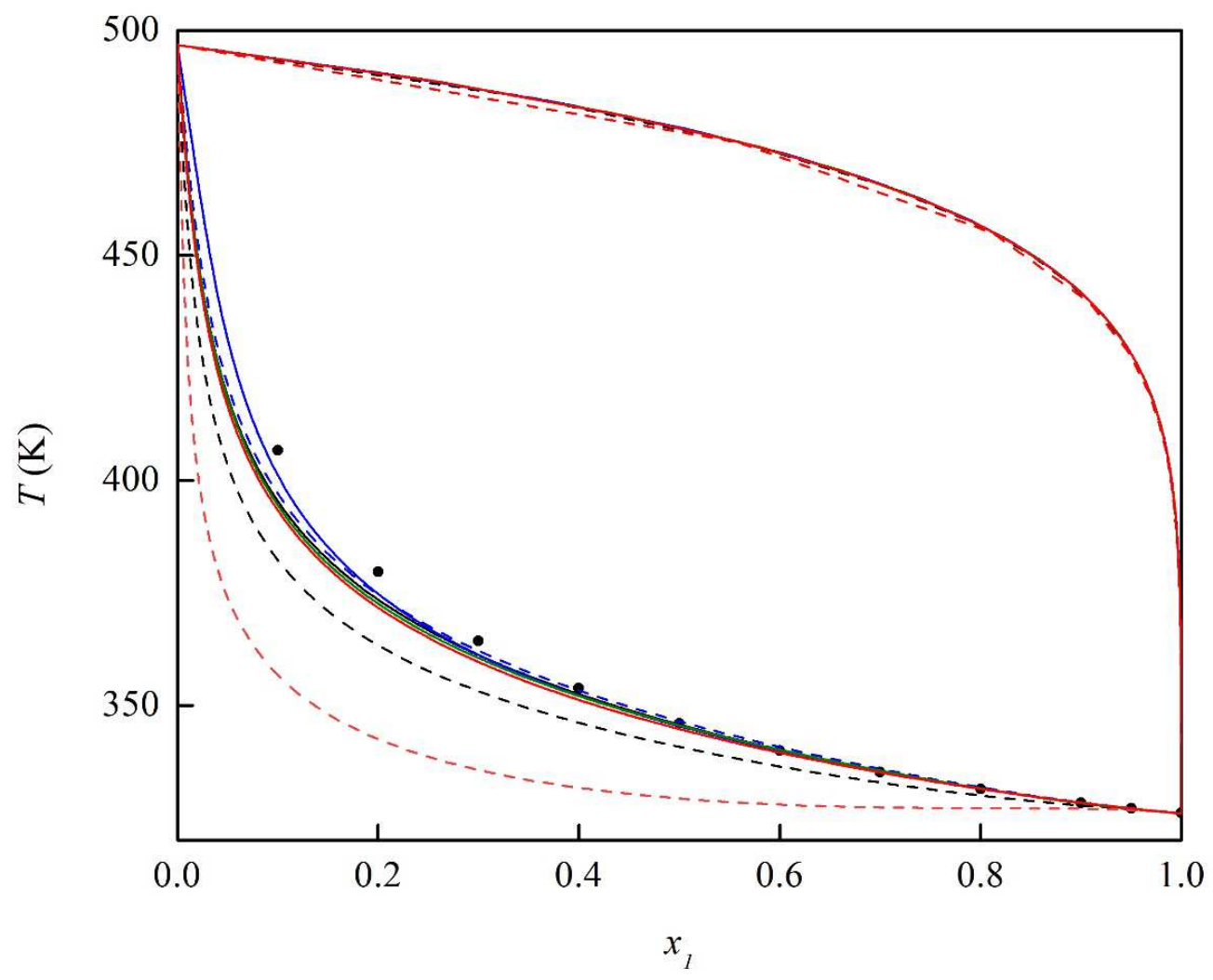

278 Figure 2. Binary system water $\left(x_{1}\right)+$ glycerol $\left(x_{2}\right)$ at $14.19 \mathrm{kPa}$. Experimental data [22] $(\bullet)$. Published parameters models: Original- (--), Linear- (--) Modified- (--) and Dortmund-UNIFAC (--). Lipids-based group interaction parameters models: Original- (-), Linear- (-), Modified- (-) and Dortmund$\operatorname{UNIFAC}(-)$

The new group $\mathrm{OH}_{\text {acyl }}$ introduced for the UNIFAC-based models with lipids-based group-

284 interaction parameters, demonstrated improved predictions for mixtures with acylglycerols, such

285 as monoacylglycerols, when compared with the UNIFAC-based models using the published

286 parameters. Figure 3 shows a poor prediction of the Modified- and Dortmund-UNIFAC models

287 using the published parameters. Both models with published parameters overestimate the

288 temperature of monoacylglycerols + fatty acids systems. 


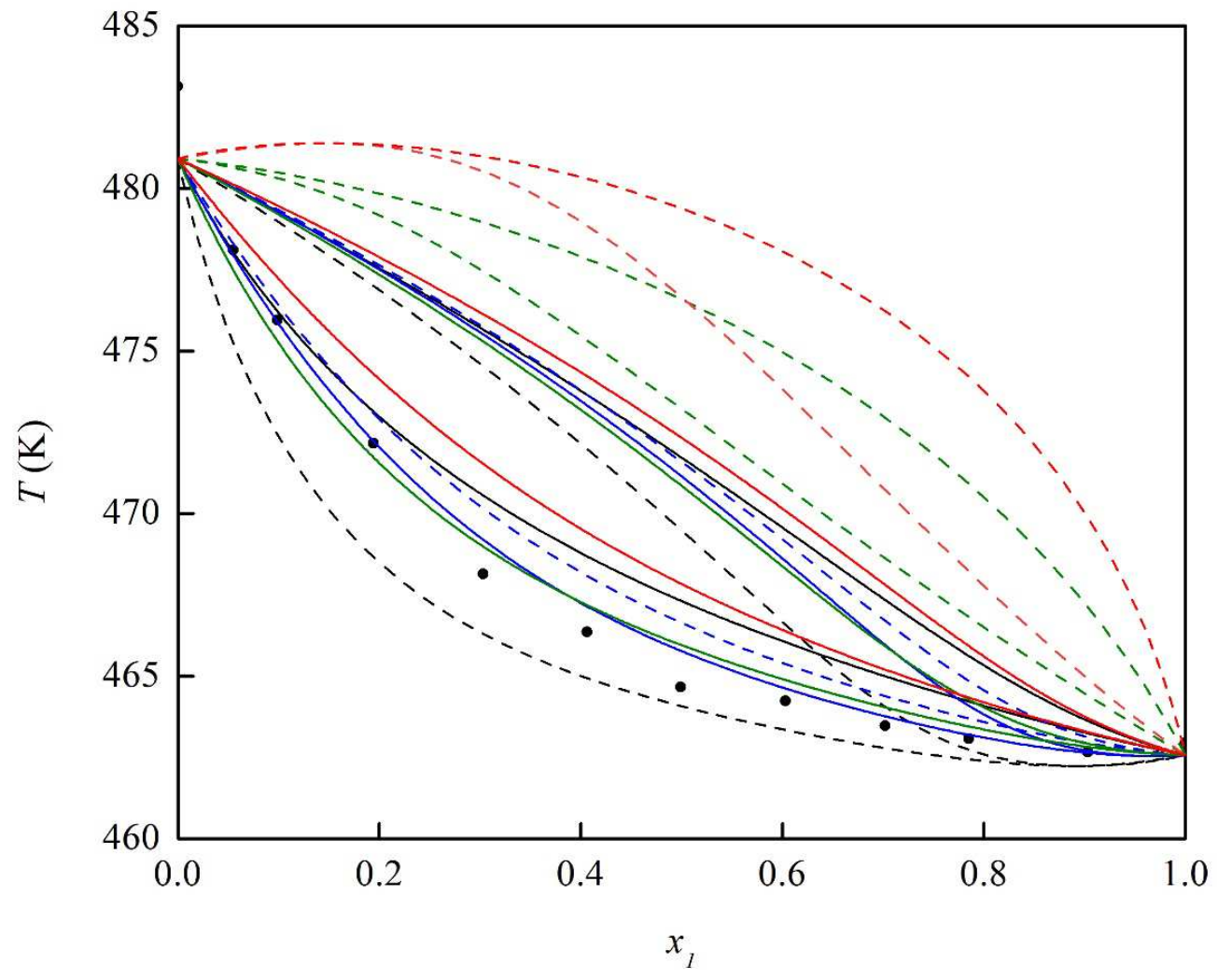

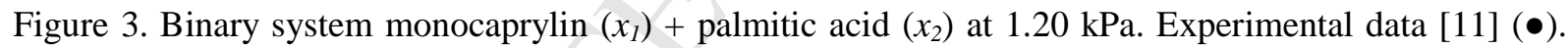
Published parameters models: Original- (--), Linear- (--) Modified- (--) and Dortmund-UNIFAC (--). Lipids-based group interaction parameters models: Original- (-), Linear- (-), Modified- (-) and Dortmund-UNIFAC (-)

Figure 4 shows the total value of ARD (\%) versus number of data points for the UNIFAC-based models with lipids group-interaction parameters. It is possible to observe that the model with the 297 lowest deviation is the Linear-UNIFAC model, while Original-UNIFAC has the highest 298 deviation. Among all models, Original-UNIFAC is the only one with temperature-independent 299 parameters, and has thus fewer adjustable parameters compared to the other three UNIFAC variant models. Figure 5 presents the total ARD (\%) versus the number of data points for the 
301 Linear-UNIFAC model with published and lipids group-interaction parameters, which shows an improvement for the lipids-based model.

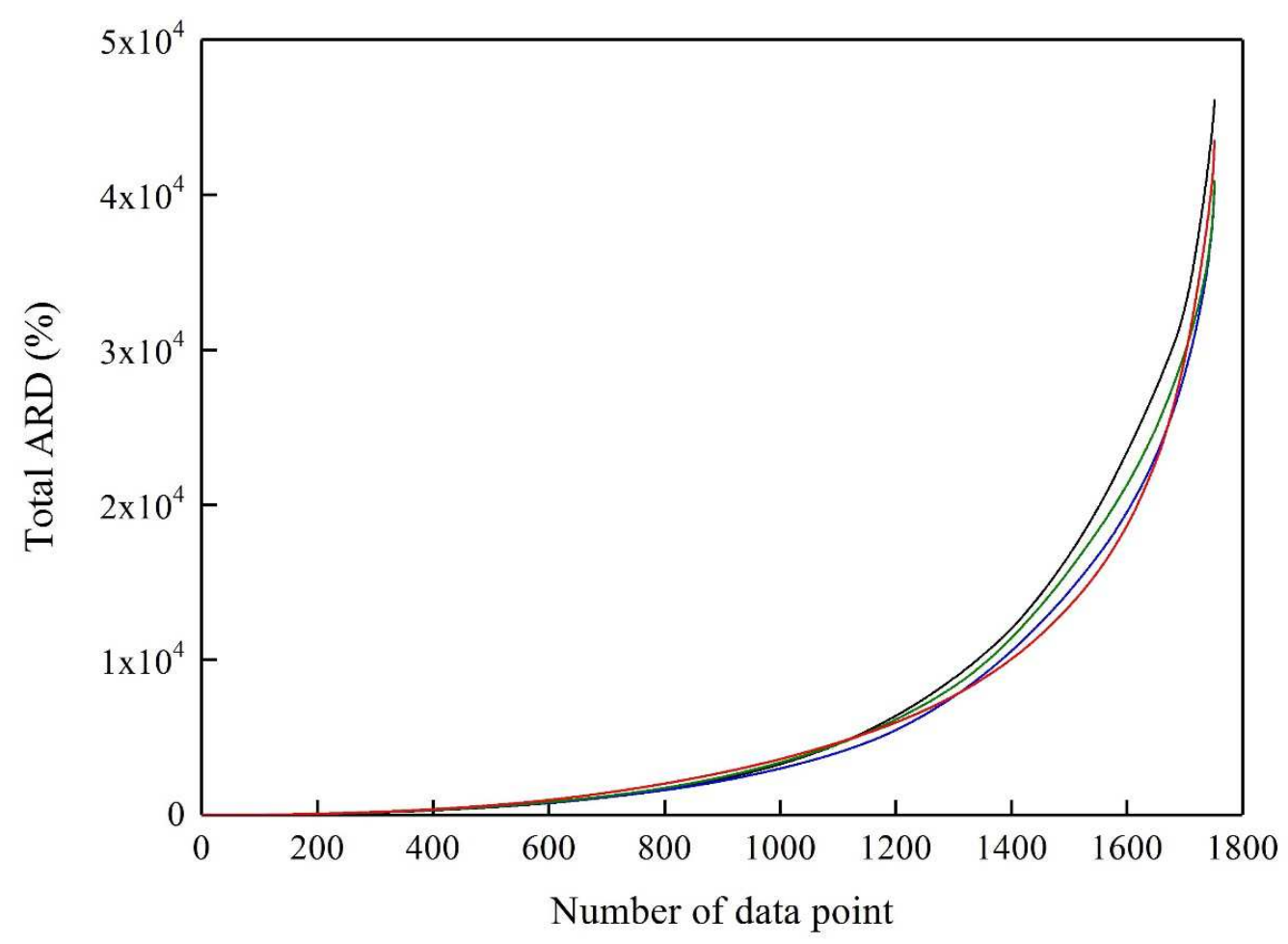

Figure 4. Total ARD (\%) for the Original- (-), Linear- (-), Modified- (-) and Dortmund-UNIFAC 306 (-) using the lipids-based group interaction parameters for the UNIFAC models versus the total number of data points 


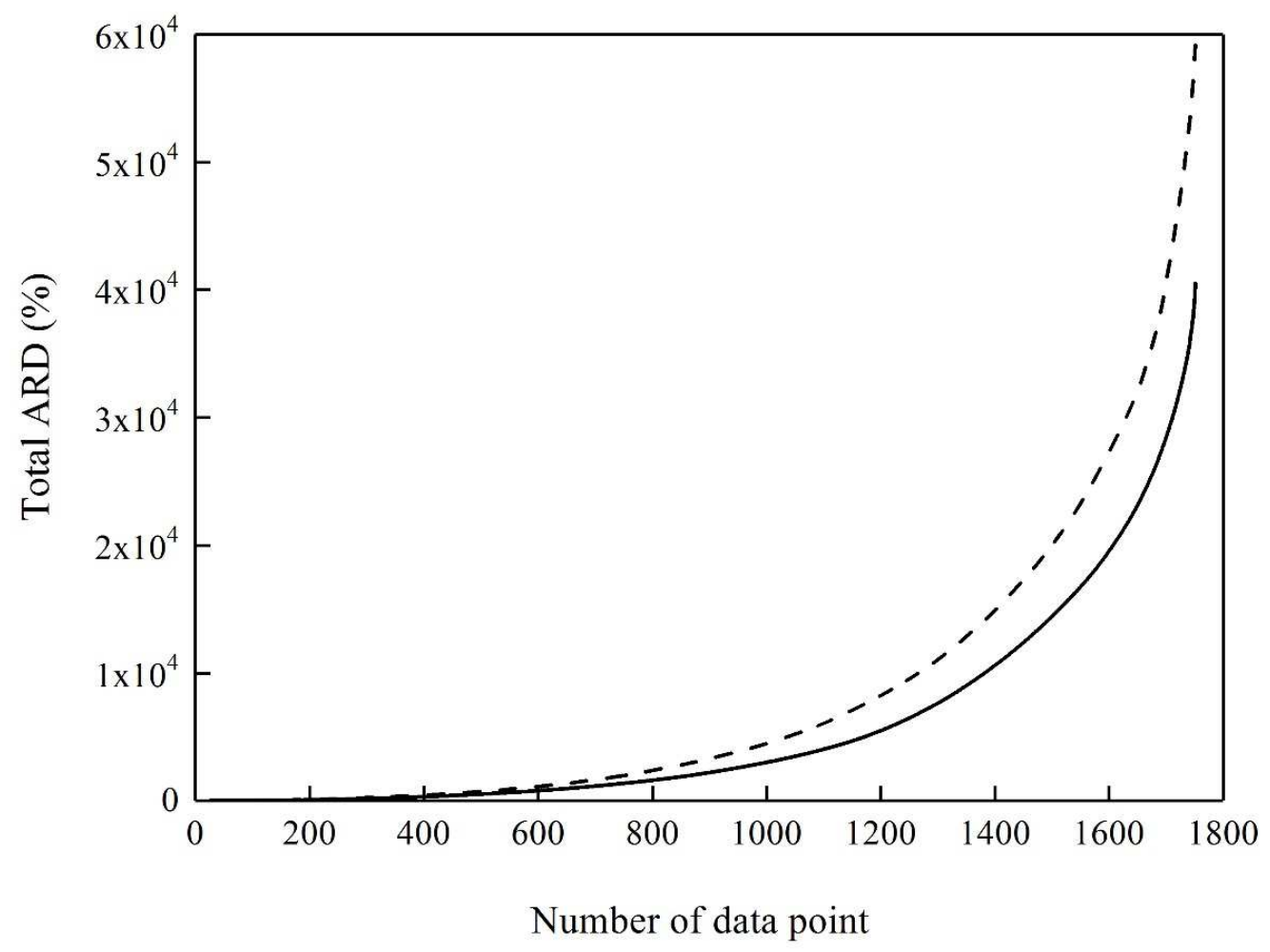

Figure 5. Total ARD (\%) for the published parameters of the Original-UNIFAC (--), and the lipids groupinteraction parameters for the Linear-UNIFAC $(-)$ versus the total number of data points

312 The parity plots, experimental vs. calculated pressure for all data points, varying from subatmospheric pressure to $\approx 101 \mathrm{kPa}$ (except for the glycerol systems), and for all UNIFAC-based models with published and lipids group-interaction parameters are presented in Figure 6. The glycerol systems were not included due to the large deviations for both sets of parameter values. Figure 6 (a) and (b) shows that Original- and Linear-UNIFAC models with published and lipidsbased group-interaction parameters underestimate the pressure values for lipids systems. On the

318 other hand, Figure 6 (c) for the Modified-UNIFAC model with both sets of parameters shows that this model tends to overestimate the pressure of the lipids systems. The Dortmund-UNIFAC model with published parameters underestimates the pressure, while using the lipids group-

321 interaction parameters, an overestimation of the pressure is observed. For all models, published 322 and lipids UNIFAC, a high deviation is observed, around $100 \mathrm{kPa}$, when compared with data at 
lower pressures (e.g.: systems with alcohol compounds), though, with the lipids-based groupinteraction parameters it is possible to observe a lower deviation.
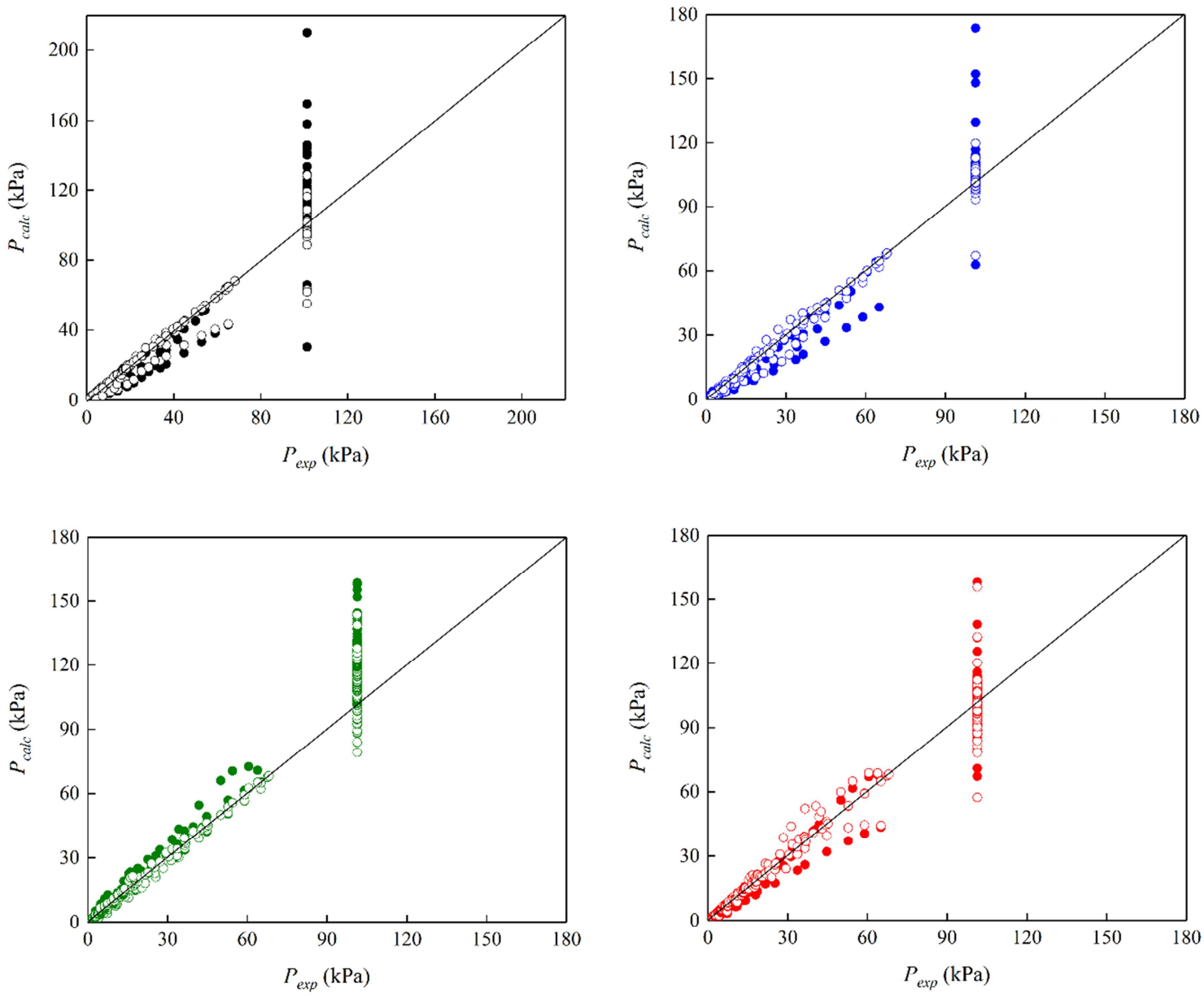

Figure 6. Experimental pressure $\left(P_{\text {exp }}\right)$ versus calculate pressure $\left(P_{\text {calc }}\right)$ of all data points (except for glycerol mixtures) using published parameters Original-UNIFAC $(\bullet)$, lipids group-interaction parameters Original-UNIFAC $(\bigcirc)$, published parameters Linear-UNIFAC $(\bullet)$, lipids group-interaction parameters Linear-UNIFAC $(O)$, published parameters Modified-UNIFAC $(\bullet)$, lipids group-interaction parameters Modified-UNIFAC $(\bigcirc)$ and published parameters Dortmund-UNIFAC ( $)$, lipids groupinteraction parameters Dortmund-UNIFAC $(\bigcirc)$, 
337 Table 6. Group-interaction parameters $a_{m n}, a_{m n}$ and $a_{m n 2}$ for the Original-, Linear-, Modified- and Dortmund-UNIFAC models fitted to lipid data

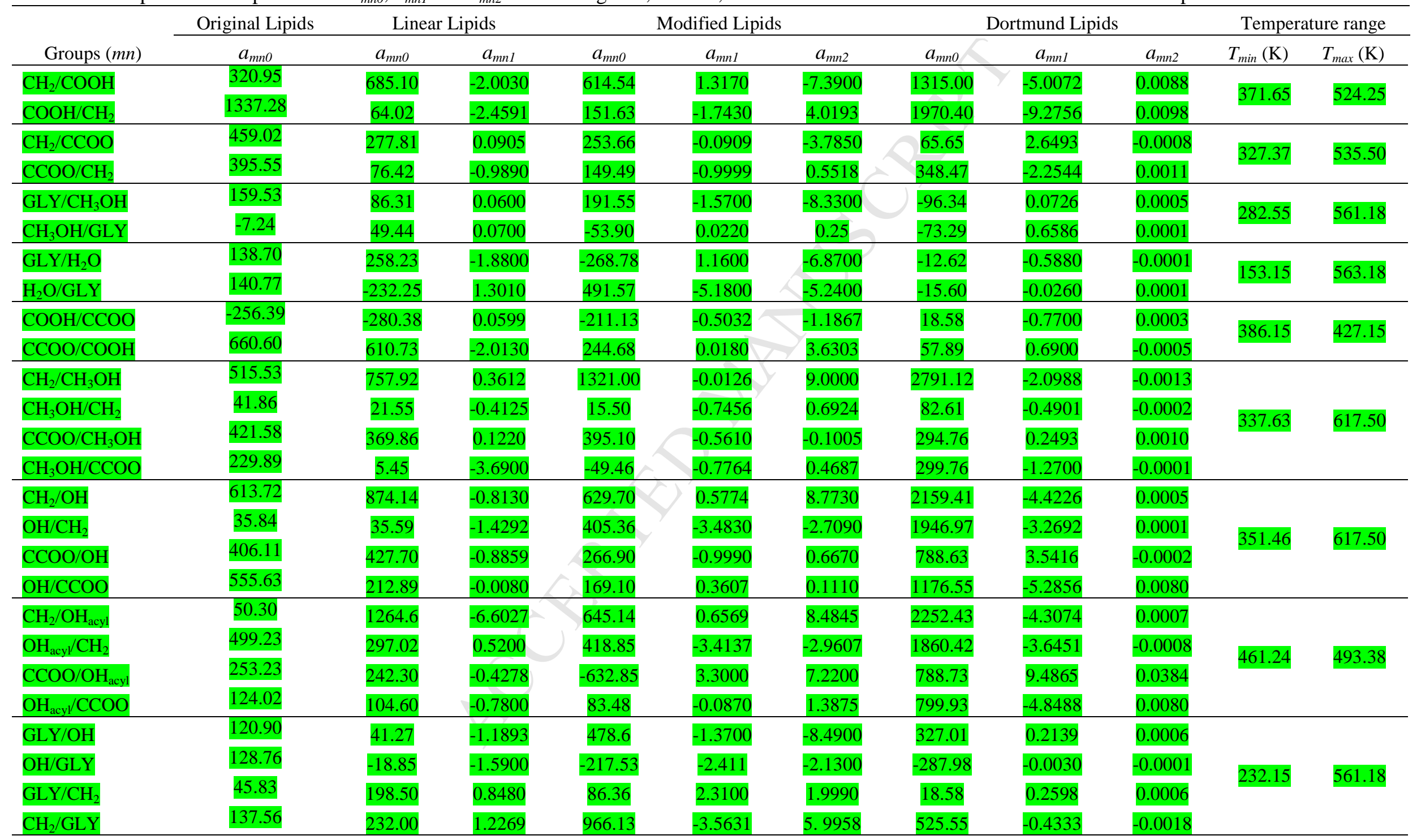




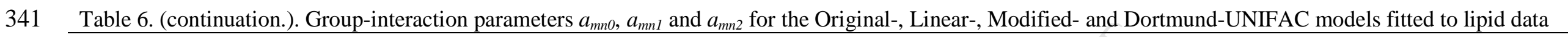

\begin{tabular}{|c|c|c|c|c|c|c|c|c|c|c|c|}
\hline \multirow[b]{2}{*}{ Groups $(m n)$} & \multirow{2}{*}{$\begin{array}{c}\text { Original Lipids } \\
a_{m n 0} \\
\end{array}$} & \multicolumn{2}{|c|}{ Linear Lipids } & \multicolumn{3}{|c|}{ Modified Lipids } & \multicolumn{3}{|c|}{ Dortmund Lipids } & \multicolumn{2}{|c|}{ Temperature range } \\
\hline & & $a_{m n 0}$ & $a_{m n 1}$ & $a_{m n 0}$ & $a_{m n 1}$ & $a_{m n 2}$ & $a_{m n 0}$ & $a_{m n 1}$ & $a_{m n 2}$ & $T_{\min }(\mathrm{K})$ & $T_{\max }(\mathrm{K})$ \\
\hline $\mathrm{COOH} / \mathrm{CH}=\mathrm{CH}$ & 1318.50 & -647.09 & -5.0780 & 227.30 & -9.1300 & 7.2000 & -347.50 & 0.4466 & -0.0026 & \multirow{4}{*}{318.14} & \multirow{4}{*}{481.08} \\
\hline $\mathrm{CH}=\mathrm{CH} / \mathrm{COOH}$ & 998.30 & 4334.00 & 0.1008 & 143.39 & -0.8700 & -0.1777 & -2026.10 & 6.7093 & -0.0046 & & \\
\hline $\mathrm{CH}_{2} / \mathrm{CH}=\mathrm{CH}$ & 125.74 & -102.30 & 0.1679 & 245.29 & -0.1834 & -0.3660 & 518.75 & -0.2723 & 0.0033 & & \\
\hline $\mathrm{CH}=\mathrm{CH} / \mathrm{CH}_{2}$ & 555.93 & 144.80 & -0.2720 & -46.45 & -0.1817 & -1.4700 & -29.00 & 0.0803 & 0.0004 & & \\
\hline $\mathrm{CCOO} / \mathrm{CH}=\mathrm{CH}$ & 135.28 & 200.62 & 7.0201 & 524.35 & 1.2210 & 4.7700 & -546.07 & -0.7768 & -0.0011 & \multirow{2}{*}{318.14} & \multirow{2}{*}{514.61} \\
\hline $\mathrm{CH}=\mathrm{CH} / \mathrm{CCOO}$ & 54.61 & -153.14 & 4.7899 & -24.00 & 0.6530 & 0.0700 & 981.10 & -0.9514 & -0.0015 & & \\
\hline $\mathrm{COOH} / \mathrm{OH}_{\text {acyl }}$ & -129.89 & -39.43 & 2.5500 & -15.76 & -1.0721 & 0.3364 & 2654.44 & -4.8021 & 0.0004 & \multirow{2}{*}{462.67} & \multirow{2}{*}{498.35} \\
\hline $\mathrm{OH}_{\text {acyl }} / \mathrm{COOH}$ & 222.89 & 872.19 & -5.7000 & 213.59 & 0.6206 & -0.9373 & 918.67 & 4.9300 & -0.008 & & \\
\hline $\mathrm{CH}=\mathrm{CH} / \mathrm{CH}_{3} \mathrm{OH}$ & 1424.55 & 875.80 & -7.5100 & 3056.13 & 3.0000 & 1.9600 & -726.27 & 9.6322 & -0.0163 & \multirow{2}{*}{338.28} & \multirow{2}{*}{387.11} \\
\hline $\mathrm{CH}_{3} \mathrm{OH} / \mathrm{CH}=\mathrm{CH}$ & 64.65 & -110.20 & 2.9200 & -102.00 & 0.2710 & 0.8500 & -103.71 & 0.6024 & -0.0019 & & \\
\hline $\mathrm{CH}=\mathrm{CH} / \mathrm{OH}$ & 384.72 & 984.73 & -4.1293 & 1192.06 & 3.4403 & -1.4330 & 2903.73 & -5.9300 & 0.0048 & \multirow{2}{*}{318.15} & \multirow{2}{*}{617.42} \\
\hline $\mathrm{OH} / \mathrm{CH}=\mathrm{CH}$ & 407.71 & 215.88 & -5.9670 & 800.02 & -8.1016 & 0.0320 & 1281.84 & -6.5900 & 0.0052 & & \\
\hline $\mathrm{COOH} / \mathrm{CH}_{3} \mathrm{OH}$ & 2981.07 & -63.07 & 9.7476 & 714.07 & 9.6100 & 3.6990 & 1077.72 & -3.4269 & 0.0001 & \multirow{2}{*}{\multicolumn{2}{|c|}{318.15}} \\
\hline $\mathrm{CH}_{3} \mathrm{OH} / \mathrm{COOH}$ & -272.84 & 52.19 & -5.7800 & -321.10 & -7.1201 & 3.0110 & -761.76 & 2.2449 & -0.0003 & & \\
\hline $\mathrm{COOH} / \mathrm{OH}$ & 37.73 & -267.59 & 1.8507 & -75.83 & 0.8131 & 0.6300 & 1531.83 & -4.8965 & 0.0007 & \multirow{2}{*}{\multicolumn{2}{|c|}{318.15}} \\
\hline $\mathrm{OH} / \mathrm{COOH}$ & 294.83 & 513.52 & -4.9999 & 35.55 & -1.3114 & 0.3400 & -1323.86 & 4.2727 & -0.0002 & & \\
\hline $\mathrm{CCOO} / \mathrm{CH}_{2} \mathrm{CO}$ & 778.64 & 327.78 & 0.2500 & 43.65 & 0.1905 & 0.0030 & 113.15 & 0.4210 & -0.0001 & \multirow{6}{*}{\multicolumn{2}{|c|}{318.15}} \\
\hline $\mathrm{CH}_{2} \mathrm{CO} / \mathrm{CCOO}$ & 44.62 & 33.37 & -2.4311 & -11.93 & -0.0406 & 0.0010 & -4.61 & -0.2792 & 0.0001 & & \\
\hline $\mathrm{CH}=\mathrm{CH} / \mathrm{CH}_{2} \mathrm{CO}$ & 528.31 & 607.86 & 7.0965 & 1217.00 & 9.7600 & 1.0080 & 485.78 & 0.6991 & -0.0001 & & \\
\hline $\mathrm{CH}_{2} \mathrm{CO} / \mathrm{CH}=\mathrm{CH}$ & -153.42 & -176.49 & -9.6200 & -72.75 & 3.5800 & -0.1090 & 107.82 & -1.5500 & -0.0001 & & \\
\hline $\mathrm{CH}_{2} / \mathrm{CH}_{2} \mathrm{CO}$ & 529.15 & 525.94 & 4.4100 & 476.78 & -5.2902 & 1.8030 & 568.85 & 0.1403 & -0.0001 & & \\
\hline $\mathrm{CH} 2 \mathrm{CO} / \mathrm{CH}_{2}$ & 13.51 & 13.24 & -2.8907 & 71.93 & -9.2220 & -2.9160 & 150.59 & -0.8800 & -0.0001 & & \\
\hline $\mathrm{COOH} / \mathrm{CH}_{2} \mathrm{CO}$ & 39.48 & -17.25 & 5.5567 & -183.43 & 9.2540 & -6.0396 & 356.88 & -0.8000 & 0.0001 & \multirow{2}{*}{303.13} & \multirow{2}{*}{318.15} \\
\hline $\mathrm{CH}_{2} \mathrm{CO} / \mathrm{COOH}$ & 247.02 & 24.81 & -0.6438 & 282.94 & 0.7244 & 1.0960 & -156.75 & 0.8200 & -0.0001 & & \\
\hline
\end{tabular}


42 Table 7. ARD (\%) between experimental and predicted bubble-point pressured using UNIFAC models with the published and lipids-based group interaction

parameters. The lipids-based group interaction parameters for Linear-, Modified- and Dortmund-UNIFAC are from this work.

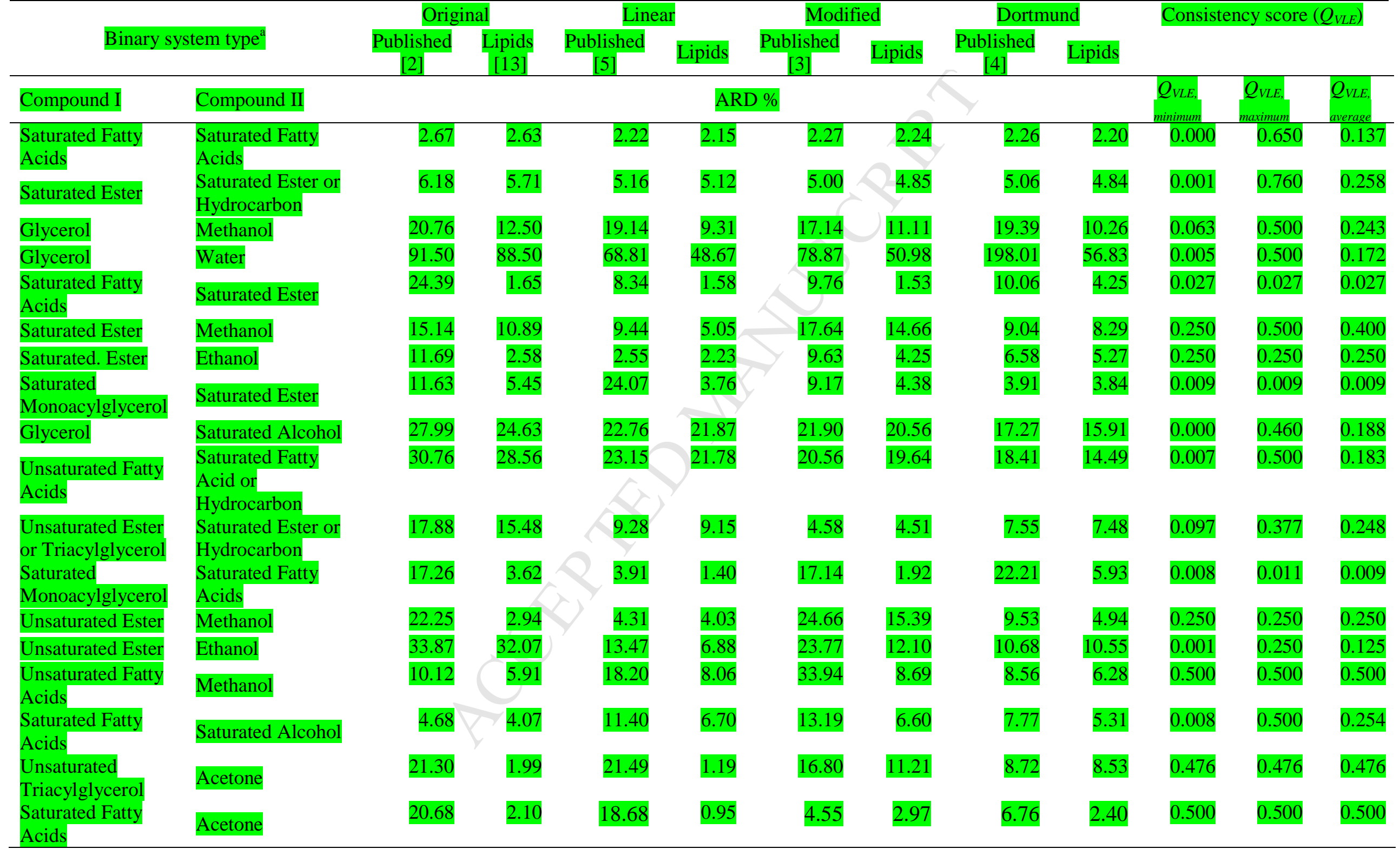


ARD (\%) for all model

$21.71 \quad 13.96$

$15.91 \quad 8.88$

18.36

10.98

20.65

9.87

${ }^{a}$ The binary systems tested are from the SPEED Lipids database. 
The parameters obtained for each UNIFAC model are further validated by checking their prediction capability for lipids SLE data. As mentioned previously, SLE data is not used for the regression of the parameters. The SLE data is extracted from the SPEED Lipids Database [13]. The SLE data is organized in category-groups in the same way as the VLE data, by applying the data organization algorithm (Algorithm A). For consistency, the same name category-groups are used for describing the SLE data sets. A new category-group is defined for SLE, named "Others". This category-group contains unsaturated triacylglycerols - saturated fatty acids and saturated triacylglycerols - unsaturated fatty acids type of systems. Available SLE data used in this study is given in Table 8 .

All the SLE calculations are performed with ICAS-MoT [26]. SLE is calculated using Eq. 11.

The melting temperature $\left(T_{m}\right)$ is taken from literature when data is available; otherwise values from SPEED Lipids Database [13] are used. The heat of fusion $\left(H_{f}\right)$ values are taken from SPEED Lipids Database.

$$
\ln \left(x_{i}\right)=\ln \gamma_{i}+H_{f}\left(\frac{1}{T_{m, i}}-\frac{1}{T}\right)
$$

360 where $x_{i}$ is the mole fraction of the compound with higher melting point, $\gamma_{i}$ is the activity 361 coefficient of compound $i, H_{f}$ is the fusion enthalpy of compound $i, T_{m, i}$ is the melting point of 362 compound $i$, and $T$ is the mixture melting temperature.

363 The results obtained for each category-group, with all UNIFAC-based models, using both 364 published and lipids-based group-interaction parameters are given in Table 9. A slight 365 improvement is noticed for Modified-UNIFAC model using the lipids-based group-interaction 366 parameters compared to the published parameters, except for Linear- and Dortmund-UNIFAC 
model. This bigger deviation for Dortmund-UNIFAC with lipids group-interaction parameters could be due to the $R_{k}$ and $Q_{k}$ parameters, which are not regressed for lipids systems in this work. Also, the extrapolation of the parameters to outside the range of temperatures and phase equilibria type could affect the prediction of this models. From all UNIFAC-based models using published parameters, the best performance is obtained with Dortmund-UNIFAC model (ARD = $1.34 \%)$ followed by Linear-UNIFAC model $(A R D=1.35 \%)$. Using the lipids group-interaction parameters, again the best overall results is provided Linear-UNIFAC model (ARD $=1.43 \%)$. Analyzing the deviations for each-category group, the best performances are in general when lipids group-interaction parameters are used. It is important to emphasize, that for the SLE prediction, the parameters are not only extrapolated to another type of phase equilibria, but also to another range of temperatures (see also Table 6 and Table 8), so unexpected behavior may occur.

379 An example of SLE prediction is presented in Figure 7, where the best performances are shown 380 for different UNIFAC-based models (see also Table 9). In Figure 7, the prediction for system 381 ethyl linoleate + ethyl stearate [27] is presented for Linear, Modified and Dortmund UNIFAC 382 models using lipids-based group-interaction parameters, all models presented analogous 383 behavior. 


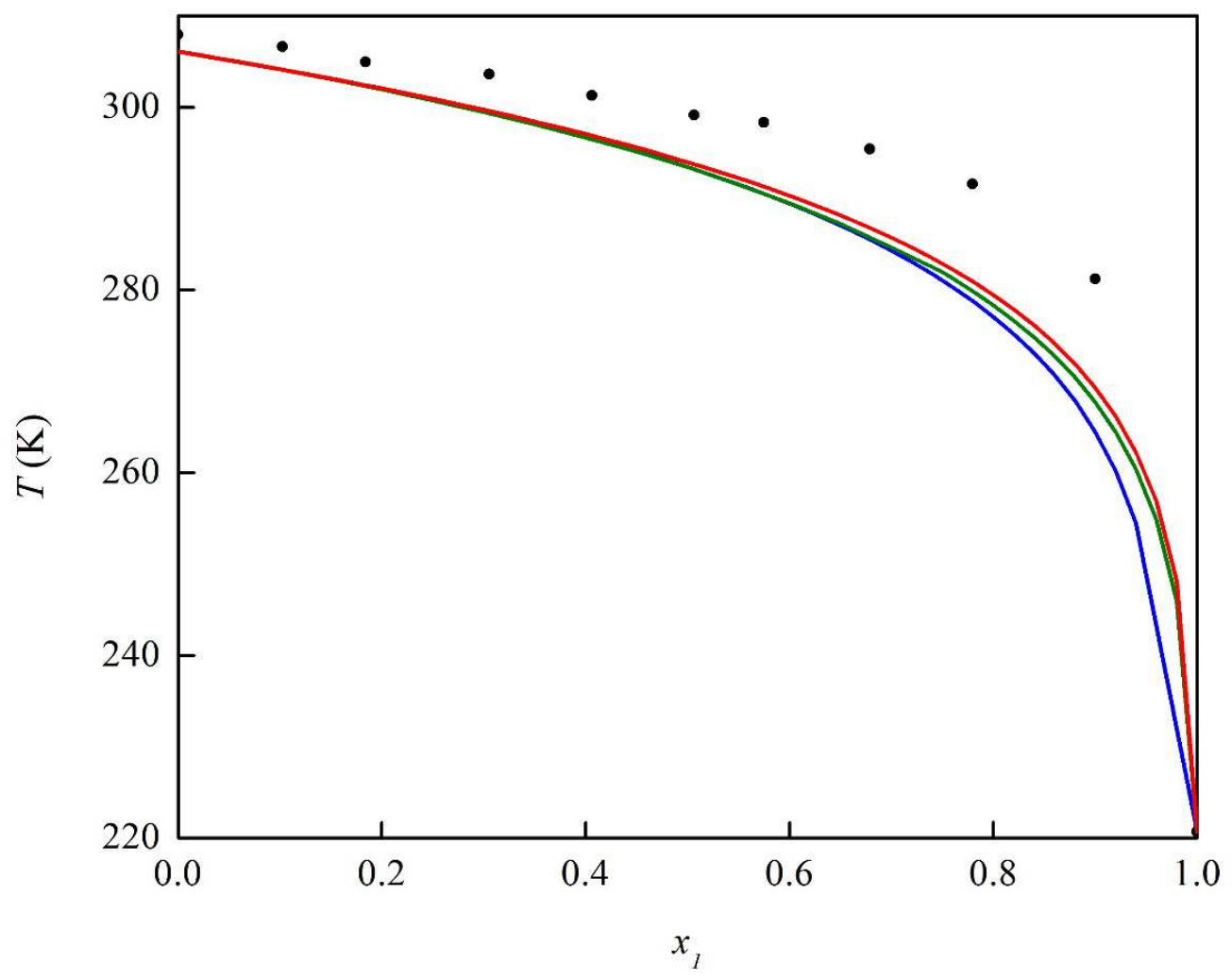
systems involved.

Figure 7. SLE system ethyl linoleate $\left(x_{1}\right)+$ ethyl stearate $\left(x_{2}\right)$. Experimental data [27] $(\bullet)$. Lipids-based group interaction parameters UNIFAC models: Linear (-), Modified (一) and Dortmund (一)

The extrapolation results do show that in general the lipids group-interaction parameters can be used for SLE predictions, nonetheless one should use them with some care since different temperature ranges and behaviors are encountered for this type of systems and this form of phase equilibria. It cannot be concluded that one model works best for all type of SLE systems, but the selection of a model for performing SLE prediction should be done according to the type of SLE 
Table 8. Database used for the SLE predictions with UNIFAC models.

\begin{tabular}{|c|c|c|c|c|c|c|}
\hline \multirow{2}{*}{$\begin{array}{l}\text { Categ } \\
\text { ory- } \\
\text { group }\end{array}$} & \multirow{2}{*}{\multicolumn{2}{|c|}{ System type }} & \multirow[b]{2}{*}{$\begin{array}{l}\text { Constitutive } \\
\text { groups }\end{array}$} & \multirow[b]{2}{*}{$\begin{array}{c}\text { SLE } \\
\text { datasets }\end{array}$} & \multicolumn{2}{|c|}{ Temperature range } \\
\hline & & & & & $\begin{array}{c}T_{\text {minimum }} \\
(\mathrm{K})\end{array}$ & $\begin{array}{c}T_{\text {maximum }} \\
(\mathrm{K})\end{array}$ \\
\hline 1.1.1. & $\begin{array}{l}\text { Saturated Fatty } \\
\text { Acids }\end{array}$ & $\begin{array}{l}\text { Saturated Fatty } \\
\text { Acids }\end{array}$ & $\mathrm{CH}_{2} \mathrm{COOH}$ & 12 & 278.36 & 343.98 \\
\hline 1.1.2. & Saturated Ester & Saturated Ester & $\mathrm{CH}_{2} \mathrm{CCOO}$ & 9 & 272.51 & 314.07 \\
\hline 3.2.5. & $\begin{array}{l}\text { Unsaturated } \\
\text { Fatty Acids }\end{array}$ & Sat. FA & $\begin{array}{l}\mathrm{CH}_{2} \mathrm{COOH} \\
\mathrm{CH}=\mathrm{CH}\end{array}$ & 5 & 264.99 & 342.25 \\
\hline 3.2 .6 . & $\begin{array}{l}\text { Unsaturated } \\
\text { Ester } \\
\text { Saturated } \\
\text { Triacylglycerol }\end{array}$ & $\begin{array}{l}\text { Saturated Ester } \\
\text { Unsaturated } \\
\text { Triacylglycerol }\end{array}$ & $\begin{array}{l}\mathrm{CH}_{2} \mathrm{CH}=\mathrm{CH} \\
\mathrm{CCOO}\end{array}$ & 8 & 220.68 & 338.79 \\
\hline 6.3.2. & $\begin{array}{l}\text { Saturated Fatty } \\
\text { Acids }\end{array}$ & Acetone & $\begin{array}{l}\mathrm{CH}_{2} \mathrm{CH}=\mathrm{CH} \\
\mathrm{CH}_{2} \mathrm{CO} \\
\mathrm{COOH}\end{array}$ & 1 & 333.71 & 329.95 \\
\hline $\begin{array}{l}\text { Other } \\
*\end{array}$ & $\begin{array}{l}\text { Unsaturated } \\
\text { Triacylglycerol } \\
\text { Saturated } \\
\text { Triacylglycerol }\end{array}$ & $\begin{array}{l}\text { Saturated Fatty } \\
\text { Acids } \\
\text { Unsaturated } \\
\text { Fatty Acids }\end{array}$ & $\begin{array}{l}\mathrm{CH}_{2} \mathrm{CH}=\mathrm{CH} \\
\mathrm{CH}_{2} \mathrm{COO} \\
\mathrm{COOH}\end{array}$ & 9 & 258.62 & 342.25 \\
\hline Total & & & & 44 & 220.68 & 343.98 \\
\hline
\end{tabular}

400

401 Table 9. SLE prediction for Linear, Modified and Dortmund-UNIFAC using published and lipids-based 402 group interaction parameters.

\begin{tabular}{|c|c|c|c|c|c|c|}
\hline \multirow{3}{*}{ Category-Group } & \multicolumn{2}{|c|}{ Linear } & \multicolumn{2}{|c|}{ Modified } & \multicolumn{2}{|c|}{ Dortmund } \\
\hline & Published [5] & Lipids & Published [3] & Lipids & Published [5] & Lipids \\
\hline & \multicolumn{4}{|c|}{$\operatorname{ARD}(\%)$} & \multirow[b]{2}{*}{0.92} & \multirow[b]{2}{*}{0.92} \\
\hline 1.1 .1 & 0.94 & 0.94 & 0.92 & 0.92 & & \\
\hline 1.1 .2 & 1.25 & 1.25 & 1.15 & 1.33 & 1.16 & 1.15 \\
\hline 3.2 .5 & 0.36 & 1.66 & 0.38 & 0.42 & 0.43 & 0.56 \\
\hline 3.2 .6 & 2.33 & 2.37 & 2.35 & 2.33 & 2.32 & 2.32 \\
\hline 6.3 .2 & 0.35 & 0.19 & 2.21 & 2.18 & 1.43 & 1.43 \\
\hline Other & 2.88 & 2.20 & 4.76 & 3.51 & 1.78 & 3.77 \\
\hline Total ARD $(\%)^{\mathrm{b}}$ & 1.35 & 1.43 & 1.96 & 1.78 & 1.34 & 1.69 \\
\hline${ }^{\mathrm{a}} A R D(\%)=1 / N \sum_{i=1}^{N}$ & $\frac{{ }^{\text {rimental }}-T^{\text {cal }}}{T^{\text {experimental }}}$ & 100 & & $X$ & & \\
\hline
\end{tabular}




\section{Conclusions}

The method of Perederic et al. [2017] was successfully applied for the binary interaction parameter estimation for three UNIFAC-based models: Linear, Modified and Dortmund. For the estimation of the binary group interaction parameters, the SPEED Lipids Database was used for VLE data collection, and the same data sets were used as in Perederic et al. [2017]. Two new functional groups were added for the description of acylglycerols $\left(\mathrm{OH}_{\mathrm{acyl}}\right)$ and glycerol (GLY) compounds for all models for improving their prediction capabilities for lipids, as was also done for Original-UNIFAC [13].

414 The estimated group-interaction parameters have been validated by checking their performances 415 on all VLE data sets available in the SPEED Lipids Database. All UNIFAC-based models 416 present better performances with the new sets of binary group-interaction parameters compared to the original published parameters. Among all the models, the Linear-UNIFAC model has been found to give the best overall performance for VLE predictions. Addition of the $\mathrm{OH}_{\text {acyl }}$ improves qualitatively and quantitatively the VLE prediction of acylglycerol systems. For the glycerol systems, introduction of the GLY group results in a significant improvement in the VLE prediction, but the deviations remain quite high for all models considered. This is a limitation of the group contribution concept for the description of systems containing compounds with many $\mathrm{OH}$ groups attached to the adjacent carbon atoms, such as glycerol, that has three $\mathrm{OH}$ groups.

424 For strongly hydrogen bonding systems, the group contribution concept does not work very well 425 and more advanced models are needed e.g. association equations of state like CPA [23] and 426 SAFT [24]. 
427 The parameters are also tested for SLE predictions for lipids systems. All the SLE datasets are

428 collected from the SPEED Lipids Database. For the UNIFAC with lipids group-interaction 429 parameters, a slight improvement in SLE prediction is observed for Modified-UNIFAC model

430 when compared to the published parameters are used.

431 The main drawback in developing and extending the predictive capabilities of the group 432 contribution concept remains the accuracy and availability of experimental data used for 433 parameter estimation. Attention should be taken when using the parameters for other types of 434 systems and other range of temperatures than the ones used in the parameter estimation as well 435 as for strongly polar and hydrogen bonding systems for which the group contribution and local 436 composition concepts deteriorate.

437

438

439

440

441

442

443

444

445

446

447

448

449 
450

451

452

453

454

455

456

457

458

459

460

461

462

463

4641688. 2286.

[1] G. M. Kontogeorgis and G. K. Folas. Thermodynamic models for industrial applications : from classical and advanced mixing rules to association theories. Wiley, 2010.

[2] A. Fredenslund. R. Jones. J.M. Prausnitz. AIChE J. 21 (1975). pp. 1086-1099.

[3] B. Larsen. P. Rasmussen. A. Fredenslund. Ind. Eng. Chem. Res. 26 (1987). pp. 2274-

[4] U. Weidlich and J. Gmehling. Ind. Eng. Chem. Res. 26 (1987). pp. 1372-1381.

[5] H. K. Hansen, B. Coto, and B. Kuhlmann. UNIFAC with linearly temperature-dependent group-interaction parameters. Internal report. 1992.

[6] J. Gmehling. J. Li. M. Schiller. Ind. Eng. Chem. Res. 32 (1993). pp. 178-193.

[7] J. Gmehling, J. Lohmann, A. Jakob, J.D. Li, R.A. Joh. Ind. Eng. Chem. Res. 37 (1998) 4876-4882.

[8] J. Gmehling, R. Wittig, J. Lohmann, R.A. Joh. Ind. Eng. Chem. Res. 41 (2002) 16781688.

465 [9] J.W. Kang. V. Diky. M. Frenkel. Fluid Phase Equilib. 388 (2015). pp. 128-141

466 [10] B. E. Poling, J. M. Prausnitz, J. P. O’Connell. Properties of Gases and Liquids. 5ed. 467 McGraw-Hill Education. 2001. 
468 [11] L.P. Cunico. D.S. Damaceno. R.M. Matricarde Falleiro. B. Sarup. J. Abildskov. R. 469 Ceriani. R. Gani. J. Chem. Thermodyn. 91 (2015). pp. 108-115

470 [12] P. C. Belting. J. Rarey. J. Gmehling. R. Ceriani. O. Chiavone-Filho, A.J.A. Meirelles. $471 \quad$ Fluid Phase Equilib. 361 (2014). p. 215-222

472 [13] O.A. Perederic, L.P. Cunico, S. Kalakul, B. Sarup, J.M. Woodley, G.M. Kontogeorgis, R. 473 Gani. J. Chem. Thermodyn. (2017).

474 [14] I. Kikic. P. Alessi. P. Rasmussen. A. Fredenslund. Can. J. Chem. Eng., 58(1980). pp. $475 \quad 253-258$.

476 [15] Bondi, A., Physical Properties of Molecular Crystans, Liquids and Glasses, Wiley, New 477 York (1968).

478 [16] J.W. Kang, V. Diky, R. D. Chirico, J. W. Magee, C. D. Muzny, I. Abdulagatov. J. Chem. 479 Eng. Data. 55 (2010). pp. 3631-3640.

480 [17] L. P. Cunico. Modelling of Phase Equlibria and Related Properties of Mixtures Involving 481 Lipids. PhD Thesis. Technical University of Denmark (DTU), 2015.

482 [18] L.C.B.A. Bessa, M.C. Ferreira, C.R.A. Abreu, E.A.C. Batista, A.J.A. Meirelles, Fluid 483 Phase Equilib. 425 (2016) 98-107

484 [19] M. Sales-Cruz, R. Gani, Comput. Chem. Eng. 16 (2003) 209-249.

485 [20] K. Balslev, J. Abildskov, Ind. Eng. Chem. Res. 41 (2002) 2047-2057.

486 [21] J.A. Monick. H.D. Allen.C.J. Marlies. Oil Soap, 23:177 (1946). pp 177-182. 
487 [22] J. Soujanya, B. Satyavathi, and T. E. Vittal Prasad. J. Chem. Thermodyn., 42 (2010). pp. $488 \quad 621-624$.

489 [23] G.M. Kontogeorgis, M.L. Michelsen, G.K. Folas, S. Derawi, N. von Solms, E.H. Stenby. 490 Ind. Eng. Chem. Res. 2006, 45 (14). pp 4855-4868

491 [24] W.G. Chapman, K.E. Gubbins, G. Jackson, M. Radosz. Fluid Phase Equilib. 52(1989). 492 pp. 31-38J. Gross, G. Sadowski, Ind. Eng. Chem. Res. 2002, 41 (22). pp 5510-5515

493 [25] I. Tsivintzelis, A. Shahid, G.M. Kontogeorgis. Fluid Phase Equilib, 430 (2016). pp. 7549492.

495 [26] M. Sales-Cruz. R. Gani. Comput. Chem. Eng. 16 (2003). pp. 209-249.

496 [27] L. Boros. M. L. S. Batista. Raquel V. Vaz. B. R. Figueiredo. V. F. S. Fernandes. M. C. 497 Costa. M. A. Krahenbuhl. A. J. A. Meirelles. J. A. P. Coutinho. Energy Fuels. 23 (2009). pp. $498 \quad 4625-4629$. 